\title{
Can Cash Transfer Programmes Promote Household Resilience? Cross-Country Evidence from Sub-Saharan Africa
}

\author{
Solomon Asfaw and Benjamin Davis
}

\begin{abstract}
Several new initiatives of cash transfer programmes have recently emerged in sub-Saharan Africa, and most target poor rural households dependent on subsistence agriculture. This paper synthesizes the key findings of From Protection to Production Project (PtoP) of FAO and discusses the role of cash transfer programmes risk management tool to increase resilience in sub-Saharan Africa. Results show that such programmes have important implications for household resilience. Although the impacts on risk management are less uniform, the cash transfer programmes seem to strengthen community ties (via increased giving and receiving of transfers) and allow households to save and pay off debts, and decrease the need to rely on adverse risk coping mechanisms. One important finding related to climate change, as illustrated by the Zambia case, is that households receiving cash transfers suffered much less from weather shocks, with poorest households as the biggest gains, and food security increased, although differing across countries. The paper concludes that social protection programmes could be more effective as safety nets by explicitly accounting for climate risk in their design and implementation.
\end{abstract}

JEL Classification $\mathrm{I} 38 \cdot \mathrm{Q} 01 \cdot \mathrm{Q} 18$

\section{Introduction}

Almost three quarters of economically active rural populations in sub-Saharan Africa (SSA) are smallholder farmers, making them important players in national agricultural development plans. Thus agricultural development that contributes to

\footnotetext{
S. Asfaw $(\bowtie)$

FAO of the UN, Rome, Italy

e-mail: solomon.asfaw@fao.org

B. Davis

Food and Agricultural Organization (FAO) of the United Nations,

Viale delle Terme di Caracalla, 00153 Rome, Italy
} 
increasing the productivity, profitability and sustainability of smallholder farming is critical for reducing poverty and improving food security and nutrition. Agriculture in SSA, however, is increasingly exposed to a variety of risks and uncertainties, including market risk, production risks, climate variability, pest and disease outbreaks and windstorms, and institutional risks (Antonaci et al. 2012). The main premise is that by providing a steady and predictable source of income, cash transfer programmes can enhance household and community level resilience by improving human capital, facilitating changes in productive activities by relaxing liquidity constraints, improving natural resource management, and improving the ability to respond to and cope with exogenous shocks (e.g., Handa et al. 2015; Asfaw et al. 2012). The ultimate aim is to strengthen and improve resilience for rural producers to allow them to prevent future fluctuations in consumption and move to the next welfare level (Antonaci et al. 2012).

Government strategies for managing agricultural risks at the household or community level have taken different forms in different countries, but are generally classified into three groups:

1. mitigation/adaptation activities designed to reduce the likelihood of an adverse event or reduce the severity of actual losses. Risk mitigation options are numerous and varied (e.g., irrigation, use of resistant seeds, improved early warning systems, and adoption of better agronomic practices);

2. risk transfer, such as commercial insurance and hedging; and

3. resilience-improving mechanisms to withstand and cope with events ex ante.

Examples of these government strategies include social safety net programmes, buffer funds, savings, strategic reserves, contingent financing, insurance, etc. There are many definitions of resilience in the literature but the common thread in all definitions is the notion that resiliency reflects an ability to successfully manage or withstand a shock or stress (e.g., Alinovi et al. 2010).

Unlike in other parts of the world, most farmers in SSA have no access to government or market-based risk management tools; when they do, government programmes or private sector initiatives to manage price and production instability are often insufficient. Moreover, social protection programmes are seldom institutionalized, and are rarely used as risk management instruments to address food and nutrition insecurity. However, an increasing number of African governments over the last 15 years have launched social protection programmes including cash transfers, workfare and public works programmes and in-kind safety nets.

Cash transfer programmes in African countries have tended to be unconditional (where regular and predictable transfers of money are given directly to beneficiary households without conditions or labour requirements) rather than conditional (more common in Latin America and which require recipients to meet certain conditions, such as using basic health services or sending their children to school). Most of these programmes seek to reduce poverty and vulnerability by improving food consumption, nutritional and health status and school attendance. There is robust evidence from numerous countries (especially within Latin America and increasingly SSA) that cash transfers have leveraged sizeable gains in access to 
health and education services, as measured by increases in school enrolment (particularly for girls) and use of health services (particularly preventative health, and health monitoring for children and pregnant women) (e.g., Fiszbein and Schady 2009; Davis et al. 2012).

Building on the existing literature, this paper synthesizes the key findings of the From Protection to Production Project (PtoP) of FAO, which studies the impact of cash transfer programmes on household economic decision-making. The cash transfer programmes studied here are government-run cash transfer programmes in SSA. The paper is organized as follows. First we examine cross-country results to test their magnitude and distribution (i.e. heterogeneity) of impact on productivity and economic indicators, and the implications of these impacts on resilience. We will also explore the underlying programme design and implementation features that mediated the impacts. Section 2 provides an overview of the evolution of social cash transfer (SCT) programmes in SSA while Sect. 3 presents the conceptual framework on the linkages between cash transfers and economic impacts and resilience. Section 4 presents the impact evaluation design and data collection methods. Section 5 presents a synthesis of key cross-country findings, while Sec. 6 ends with a short conclusion and policy implications.

\section{Overview of selected SCT Programmes in SSA}

SCTs launched by African governments over the past 10 years have provided assistance to the elderly and to households that are ultra-poor, labour-constrained, and/or caring for orphans and vulnerable children. Typically, ministries of social development manage the programmes. The main types of social protection instruments used in African countries include cash transfers, workfare and public works programmes, and in-kind safety nets.

Workfare and public works programmes supply temporary employment to recipients able to contribute their labour in return for benefits, at the same time creating public goods in the form of new infrastructure, making improvements to existing infrastructure, or performing and delivering services (Del Ninno et al. 2009). In-kind safety nets (e.g. food aid, supplementary feeding and school feeding schemes, etc.) help recipients to access food, health care, education, and other basic goods and services. Other, more common instruments in parts of Southern Africa include social insurance schemes - primarily social pensions and health insurance.

Some of the African social protection instruments implemented during the last decade include the Kenyan Cash Transfer for Orphans and Vulnerable Children (CT-OVC), the Malawi SCTP, Mozambique's Programa de Subsidios de Alimentos (PSA), Ethiopia's PSNP, the Livelihood Empowerment Against Poverty (LEAP) programme in Ghana, the CGP in Lesotho, South Africa's Child Support Grant and Old Age Pensions, Rwanda's Vision 2020 Umurenge Programme, Burkina Faso's nationwide school feeding scheme under the Burkinabé Response to Improve Girls' Chances to Succeed (BRIGHT) integrated programme, Zambia's CGP and the 
Zimbabwe SCT. Several other countries, including Uganda, Tanzania and Liberia, have also pursued safety net programmes (Asfaw et al. 2012). Our study focuses on the programmes described in the remainder of this section.

The Lesotho CGP provides an unconditional cash transfer to poor and vulnerable households. The primary objective of the CGP is to improve the living standards of OVC including nutrition and health status and increased school enrolment (Pellerano et al. 2012). The CGP is targeted at poor households with children, including childheaded households. As of the end of 2013 the programme reached approximately 20,000 households and 50,000 children (Pellerano et al. 2014). The Kenyan CT-OVC is the Government's flagship social protection programme, reaching over 130,000 households and 250,000 OVC across the country as of the end of 2011 (Asfaw et al. 2012). In Ethiopia, the cash transfer programme initiated by Tigray regional state and UNICEF aimed to improve the quality of lives of OVCs, elderly and persons with disabilities as well as to enhance their access to essential social welfare services such as health care and education via access to schools in two selected woredas (districts) (Berhane et al. 2015).

The Malawi SCTP was initiated in 2006 in the pilot district of Mchinji, providing small cash grants to ultra-poor, labour-constrained households. The SCTP objectives included reducing poverty and hunger in vulnerable households and increasing child school enrolment. By March 2015 the SCTP covered 100,000 beneficiary households and had gone to full scale in 10 districts, and the Government of Malawi expects to have enrolled over 175,000 households by the end of 2015. The programme was fully executed by the Government of Malawi through the District Councils by Social Welfare Officers (Handa et al. 2015).

The Ghanaian LEAP programme provides cash and health insurance to extremely poor households to improve short-term poverty and encourage long-term human capital development. LEAP started a trial phase in 2008 and began expanding gradually in 2009 and 2010, currently reaching over 70,000 households with an annual expenditure of approximately USD 20 million (Handa et al. 2014). The programme is fully funded from the Government of Ghana's general revenues, and is the of its National Social Protection Strategy's flagship programme. The LEAP programme operates in all 10 regions of rural Ghana. Within regions, districts are selected for inclusion based on the national poverty map; within districts, local DSW offices choose communities based on their knowledge of relative rates of deprivation (Handa and Park 2012).

In 2010, Zambia's Ministry of Community Development and Social Services (MCDSS) began implementing its own CGP in the three districts (Kalabo, Kaputa, and Shongombo) with the highest rates of mortality, morbidity, stunting, and wasting among children under 5. The CGP includes all households with a child under five years of age. Eligible households receive 55 kwacha a month (equivalent to USD 12) irrespective of household size, an amount considered sufficient to purchase one meal a day for everyone in the household for one month. The goal of the programme is to reduce extreme poverty and the intergenerational transfer of poverty, and as of March 2014 the programme reached 20,000 ultra-poor households (Daidone et al. 2014a). 
Our impact evaluations focus on measuring the primary objectives of these programmes, including food security, health, and nutritional and educational status, particularly of children. Most programmes are located in some kind of social ministry, administered by professionals with backgrounds in the social sciences, including economists with specialization in the social sectors. The impact evaluations are most often implemented by research institutions and consulting firms with specializations in these social sectors.

\section{Role of Cash Transfer for Building Resilience: Review of Selected Evidence}

The potential benefits of cash transfer programmes are built around the premise that the provision of regular and predictable cash transfers to very poor households, in the context of missing or thin markets, has the potential to both generate economic and productive impacts at the household level (e.g., Handa et al. 2015; Asfaw et al. 2012; Covarrubias et al. 2012; Boone et al. 2013). In rural areas most beneficiaries depend on subsistence agriculture and live in places where markets for financial services (such as credit and insurance), labour, goods and inputs are lacking or do not function well. Cash transfers often represent a dominant share of household income, and can be expected to help households in overcoming the obstacles that block their access to credit or cash. This, in turn, can increase productive and other income-generating investments, influence beneficiaries' role in social networks, increase access to markets, improving the ability to deal with exogenous shocks, and strengthen household and community level resilience (Asfaw et al. 2012).

The predominant view from the literature is that social protection, including cash transfer programmes, may protect beneficiaries from shocks, reduce use of negative coping strategies that undermine longer-term livelihood sustainability, and reduce household risk adversity towards more profitable, yet more risky, activities. One group of empirical literature investigates the impact of social protection on recovery from shocks. Evidence shows that a public works programme in India reduced income fluctuations, while a public works programme in Ethiopia protected households from the negative effects of crop damage on child growth. Nonetheless, although a food-for-work programme in Ethiopia increased risk sharing within treated villages, it also reduced households' capabilities to manage idiosyncratic crop shocks - perhaps as a result of food aid crowding out informal insurance, and subsequently leaving beneficiaries inadequately insured to manage idiosyncratic risk (Dercon and Krishnan 2003). Conditional cash transfers (CCTs) in Latin America also facilitated recovery from shocks; some of the positive effects include reduced child labour in Nicaragua, protection of consumption for coffee farmers in Nicaragua and Honduras during global price drops, income diversification in Brazil and the decline in school dropouts in Mexico.

A second group of empirical studies looks at the impact of social protection on adverse coping strategies. The evidence generally shows a reduction in the use of adverse coping strategies that deplete household assets. One study finds that 
Ethiopia's PSNP dissuaded $60 \%$ of beneficiaries from engaging in distress sales during a drought (Devereux et al. 2005). The Michinji Malawi Social Cash Transfer pilot scheme reduced begging for food or money by $14 \%$, and reduced school dropout rates by $37 \%$ (Covarrubias et al. 2012). In Ghana and Kenya, the LEAP and CT-OVC programmes reduced child labour, distress asset sales and indebtedness. The impact on risk coping behaviour is also influenced by gender and programme design. In the Mchinji pilot scheme, children in female-headed households benefitted from the social cash transfer programme via a decline in non-household wage labour and an increase in participation in household chores, whereas children in male-headed households only experienced a decline in school absenteeism. Yet, these gender-specific outcomes are also a reflection of the constraints facing the households, as female-headed households are also singleguardian households that face challenges in balancing domestic work with income-generating activities (Covarrubias et al. 2012). In addition, cash and inkind transfers may increase social capital and strengthen informal safety nets and risk-sharing arrangements, provided that appropriate mechanisms and an enabling environment are created.

A third group of studies shows that SCT programmes can have impacts on household decision-making over labour supply, the accumulation of productive assets and productive activities, which would subsequently have implications for resilience. Todd et al. (2010) and Gertler et al. (2012) found that the Mexican PROGRESA programme led to increased land use, livestock ownership, crop production, agricultural expenditures and a greater likelihood of operating a microenterprise. From their analysis of a conditional cash transfer (CCT) programme in Paraguay Soares et al. (2010) found that beneficiary households invested between 45-50\% more in agricultural production and that the programme also increased the probability that households would acquire livestock by 6\%. Martinez (2004) found that the BONOSOL pension programme in Bolivia had positive impacts on animal ownership, expenditures on farm inputs, and crop output, although the specific choice of investment differed according to the gender of the beneficiary. In contrast, Maluccio (2010) found that the Red de Proteccion Social (RPS) programme in Nicaragua had muted impacts on the acquisition of farm implements and no impact on livestock or land ownership. With respect to SSA, Covarrubias et al. (2012) and Boone et al. (2013) found that the Malawi SCT Programme (SCTP) led to increased investment in agricultural assets, including crop implements and livestock and increased satisfaction of household consumption by own production. Gilligan et al. (2009) found that Ethiopian households with access to both the Productive Safety Net Programme (PSNP) as well as complementary packages of agricultural support were more likely to be food secure, to borrow for productive purposes, use improved agricultural technologies, and operate their own nonfarm business activities. In a later study, Berhane et al. (2011) found that the PSNP led to a significant improvement in food security status for those that had participated in the programme for 5 years versus those who only received 1 year of benefits. Moreover, those households that participated in the PNSP as well as the complementary programmes had signifi- 
cantly higher grain production and fertilizer use. However, beneficiaries did not experience faster asset growth (livestock, land or farm implements) as a result of the programmes (Gilligan et al. 2009).

\section{Methodology}

\subsection{Programme Evaluation Design and Data}

The core of the quantitative analysis for the Lesotho, Malawi, Zambia and Kenya studies was an experimental design impact evaluation. In Ghana and Ethiopia the evaluation designs were quasi-experimental. Table 1 summaries the key evaluation design features of the cash transfer programmes.

In Lesotho, participation in the programme was randomized at the level of the electoral district (ED). First, all 96 EDs in four community councils were paired based on a range of characteristics, with 40 pairs randomly selected for this survey. Within each selected ED, two villages (or clusters of villages) were selected, and in every cluster a random sample of 20 households were selected. Baseline survey data was collected followed by public meetings with a lottery to assign EDs (both sampled and non-sampled) to either treatment or control groups. Selecting the treatment ED after baseline survey helped to avoid anticipation effects (Pellerano et al. 2012). The baseline household survey was carried out in 2011 prior to distribution of cash transfers; a follow up panel survey took place in 2013. A total of 3102 households were surveyed; 1531 programme eligible households (766 treatment and 765 control) were used for impact evaluation analysis, with remaining 1571 programme ineligible households used for analysis of targeting and spillover effects. The baseline analysis report (Pellerano et al. 2012) shows that randomization was quite successful.

Table 1 Core evaluation designs

\begin{tabular}{l|l|l|l|l}
\hline Country & Design & $\begin{array}{l}\text { Level of randomization or } \\
\text { matching }\end{array}$ & N & $\begin{array}{l}\text { Ineligibles } \\
\text { sampled? }\end{array}$ \\
\hline Ethiopia & $\begin{array}{l}\text { Non-experimental (PSM } \\
\text { and IPW) }\end{array}$ & $\begin{array}{l}\text { Household level within a } \\
\text { village }\end{array}$ & 3351 & Yes \\
\hline Ghana & $\begin{array}{l}\text { Propensity Score } \\
\text { Matching (IPW) }\end{array}$ & Household and Region & 1504 & No \\
\hline Kenya & $\begin{array}{l}\text { Social experiment with } \\
\text { PSM and IPW }\end{array}$ & Location & 2234 & No \\
\hline Lesotho & Social experiment & Electoral District & 2150 & Yes \\
\hline Malawi & Social experiment & Village Cluster & 3200 & Yes \\
\hline Zambia & Social experiment & $\begin{array}{l}\text { Community Welfare } \\
\text { Assistance Committee }\end{array}$ & 2519 & No \\
\hline
\end{tabular}

All studies are longitudinal with a baseline and at least one post-intervention follow-up. $\mathrm{N}$ refers to households sampled at follow-up

Source: Davis and Handa (2015) 
In Kenya's CT-OVC, the impact evaluation utilized a randomized cluster longitudinal design, with the baseline quantitative survey fieldwork carried out in mid2007. Within each district, two locations were chosen randomly to receive intervention and two were selected as controls (Ward et al. 2010). This method of randomization was not as robust as in the case of Lesotho due to the fewer units over which the randomization took place. Approximately 2750 households were surveyed in seven districts (namely, Nairobi, Kwale, Garissa, Homa Baye, Migori, Kisumu and Suba). Two-thirds of households were assigned to the treatment group. These households were re-interviewed (first round) two years later, between May and July 2009 , in order to assess the impact of the programme on key welfare indicators (Ward et al. 2010). The re-interview success rate was approximately $83 \%$. The second round follow up study was conducted between May and August 2011 with a more detailed economic activity module (including wage labour, self-employment, crop and livestock activities, etc.) to capture potential investment and productive activity benefits of the programme on families. For the household level analysis, we relied on data collected at the baseline (2007) and the second round follow up in 2011, with a sample of 1811 households. However it is important to point out that for many of the outcome variables of interest to the PtoP project, we have only one data point (i.e. no baseline).

In Zambia the baseline survey was carried out in September-October 2010, with follow ups in 2012 and 2013. Communities were randomly assigned to treatment group (incorporated into the programme in December 2010) or control (to be brought into the programme at the end of 2013). Baseline data collection began prior to group assignment. The study includes 2515 households (1228 treatment and 1287 control). Analysis of the baseline data shows that randomization appears to have worked well; greater detail on the randomization process can be found in Seidenfeld and Handa (2011).

In Malawi, baseline data was collected in 2013 and a follow up survey 17 months later in 2014 (Handa et al. 2014). Treatment and control groups each represent about half of communities sampled. The sample is divided between Salima and Mangochi districts which count, respectively, 2192 and 2160 households. Of these households 1775 and 1756, respectively, meet the eligibility criteria. The longitudinal impact evaluation includes 3531 eligible households and 821 ineligible households at baseline.

In Ethiopia, the impact evaluation design was non-experimental; it follows a longitudinal design, with a baseline household survey conducted in mid-2012, followed by separate monitoring surveys, and finally a 24 month follow-up in 2014 . The evaluation sample includes three groups of households: treatment beneficiaries, control households, and ineligible households. The development of ranking lists of eligible households based on meeting targeting criteria was a vital component. Treatment and control households were both selected from the list of eligible households. The sample comprises 3664 households at baseline, of which 1629 were beneficiaries and 1589 were control households. In addition 446 sample households were randomly selected for the study from households who were non- 
eligible to receive support from the programme either because they were less poor and/or because of the presence of able-bodied members. Attrition between baseline (May-August 2012) and endline (2014) was $8.7 \%$ or $4.36 \%$ per year (Brehane et al. 2012).

The Ghanaian LEAP programme impact evaluation takes advantage of a nationally representative household survey implemented during the first quarter of 2012. It focuses on 7 districts across 3 regions (Brong Ahafo, Central, Volta). The initial treatment sample of 700 households were randomly drawn from the group of 13,500 households that were selected into the programme in the second half of 2009. Households were interviewed prior to indication of selection to lower anticipation effect. The baseline survey instrument was a reduced version of the national household survey instrument, and the national survey sample and the treatment household sample were surveyed at the same time by ISSER. The strategy was to draw the control households from the national survey using PSM techniques. A comparison group of 'matched' households were selected from the ISSER sample and reinterviewed 2 years later, in March-April 2012, along with LEAP beneficiaries to measure changes in outcomes across treatment and comparison groups (Handa and Park 2012).

\subsection{Analytical Methods}

In PtoP project impact evaluation, we seek to answer the question: "How would cash transfer beneficiaries have fared in the absence of the programme?" The identification of the counterfactual is the organizing principle of an impact evaluation as it is impossible to observe a household both participating in the programme and not. The goal is to compare participants with non-participants who are as similar as possible except for receiving the programme in order to measure the differential impact of the intervention. The "with" data are observed in a household survey that records outcomes for recipients of the intervention. The "without" data, however, are fundamentally unobserved since a household cannot be both a participant and a non-participant of the same programme (see Asfaw et al. 2012 for detail).

However, the outcomes of non-beneficiaries may still differ systematically from what the outcomes of participants would have been without the programme, producing selection bias in the estimated impacts. This bias may derive from differences in observable characteristics (e.g., location, demographic composition, access to infrastructure, wealth, etc.) or unobservable characteristics (e.g., natural ability, willingness to work, etc.). Some observable and unobservable characteristics do not vary with time (such as natural ability) while others may vary (such as skills). Furthermore the existence of unobservables correlated with both the outcome of interest and the programme intervention can result in additional bias (i.e., omitted variables). 
The validity of experimental estimators relies on the assumption that the control group units are not affected by the programme; this is also referred to as the Stable Unit Treatment Value Assumption (SUTVA) (Rubin 1980; Djebbari and Hassine 2011). However control households can be affected through market interactions and informal transaction and risk sharing (which is also known as non-market interaction). Depending on the nature of the design and the availability of data, different analytical models can be used to estimate the impact of the programme.

Towards this end, two approaches (i.e. a difference-in-difference (DD) estimator and a single difference approach combined with inverse probability weighting and propensity score matching) were used in most of the evaluations, depending on the nature of the design and availability of data (see Asfaw et al. 2012 for detail). When baseline data are not available, as is the case for some of our outcome variables in some countries, the single difference method was applied. When panel data were available with pre- and post-intervention information, which is the case with most of the countries, a DD approach was used. By taking the difference in outcomes for the treatment group before and after receiving the cash transfer, and subtracting the difference in outcomes for the control group before and after the cash transfer was disbursed, DD is able to control for pre-treatment differences between the two groups, and in particular the time invariant unobservable factors that cannot be accounted for otherwise (Wooldridge 2002).

The key assumption is that differences between treated and control households remain constant throughout the duration of the project. If prior outcomes incorporate transitory shocks that differ for treatment and comparison households, DD estimation interprets such shocks as representing a stable difference, and estimates will contain a transitory component that does not represent the true programme effect. When differences between treatment and control groups exist at baseline, the DD estimator with conditioning variables has the advantage of minimizing the standard errors as long as the effects are unrelated to the treatment and are constant over time (Wooldridge 2002). Control variables are most easily introduced by turning to a regression framework which is convenient for the DD, or by combining DD with propensity score matching or DD with inverse probability weighting (DD-IPW).

All estimators presented above assume the cash transfer impact is constant, irrespective of who receives it. The mean impact of a programme or policy based on this assumption is a concise and convenient way of evaluating impacts. Heckman et al. (1997) justify this approach if researchers and policy makers believe that (a) total output increases total welfare and (b) detrimental effects of the programme or policy on certain parts of the population are not important or are offset by transfers-either through an overarching social welfare function or from family members or social networks.

Overall mean impacts are most helpful when complemented with measurements of distributional impact. Even if the mean programme effect were significant, whether the programme had a significant beneficial or detrimental effect might vary across the distribution of targeted households (Khandker et al. 2010). For example, the impact on poorer households as compared to wealthier households is particularly interesting in the context of programmes that aim to alleviate poverty. 
There are a number of ways to present the distributional impacts of a cash transfer programme. For example, one could divide the sample of households and individuals into different demographic groups (e.g., by gender or age cohort), perform separate analysis on each group, and see if estimated impacts are different. Interacting the treatment with different household socioeconomic characteristics is another way to capture differences in programme effects, although adding too many interaction terms in the same regression can lead to issues with multicollinearity (Khandker et al. 2010). Another way to present distributional impacts of cash transfer programmes is by using a quintile regression approach to assess the magnitude of impact for each strata of households. Simply investigating changes in the mean programme effect, even across different socioeconomic or demographic groups, may not be sufficient when the entire shape of the distribution changes significantly.

\section{Results and Discussion}

In this section, we synthesize key findings from the PtoP impact evaluation reports and discuss the results over three broad groups of outcome variables linked to household resilience: risk management including climate change, investment in livelihood activities and food security. We focus on the quantitative studies and where applicable we supplement the comparative analysis with results from the qualitative evidence that report on similar outcomes. The results discussed are taken from the following references: Asfaw et al. (2014, 2015a, b, 2016), Daidone et al. (2014a, b), AIR (2013), Handa et al. (2014) and Pellerano et al. (2014).

\subsection{Can Cash Transfer Promote Ex-Post Risk Management?}

By providing a reliable income stream, cash transfer programmes improve risk management by poor rural households. An extra source of income can help households provide for school fees and discourage the need for children to drop-out to work on farms. The transfers flowing in and out of households can also change, and households may engage more in social networks through increased giving and so perhaps be able to rely on these networks in the future. Households can also use that money to pay off debts, purchase on credit, or save the cash. Table 2 presents the cross-country summary of the impact of social cash transfers on risk coping strategies, access to credit, community relations, savings, and debt payments.

Beneficiary households were found to have relied less on risk coping mechanisms thanks to cash transfers. Asfaw et al. (2015b) found households in Malawi to shift away from undesirable ganyu labor as a result of the SCTP. Handa et al. (2015) also found that the SCTP reduced paid work outside the home for children aged 10-17. In the face of negative shocks, use of the cash transfers emerged as the pri- 
Table 2 Synthesis of key findings

\begin{tabular}{|c|c|c|c|c|c|c|}
\hline & Ghana & Kenya & Lesotho & Malawi & Zambia & Ethiopia \\
\hline \multicolumn{7}{|l|}{ Ability to manage risk } \\
\hline Risk coping mechanisms & + & N/E & +++ & ++ & + & ++ \\
\hline Savings & + & $\mathrm{N} / \mathrm{E}$ & - & N/A & ++ & N/A \\
\hline Purchase on credit & + & NS & NS & - & NS & 0 \\
\hline Debt payment & ++ & N/E & - & ++ & + & $\mathrm{N} / \mathrm{E}$ \\
\hline Provide transfer & - & N/E & + & NS & $\mathrm{N} / \mathrm{E}$ & - \\
\hline Receive transfer & + & N/E & + & - & $\mathrm{N} / \mathrm{E}$ & NS \\
\hline Remittance receipt & + & N/E & - & $\mathrm{N} / \mathrm{E}$ & N/E & N/E \\
\hline \multicolumn{7}{|l|}{ Agricultural asset } \\
\hline Agricultural tools & N/E & + & + & ++ & +++ & 0 \\
\hline Livestock ownership & N/E & ++ & + & +++ & +++ & 0 \\
\hline \multicolumn{7}{|l|}{$\begin{array}{l}\text { Crop and livestock } \\
\text { production and } \\
\text { marketing }\end{array}$} \\
\hline Agricultural inputs & 0 & - & ++ & ++ & +++ & 0 \\
\hline Livestock inputs & N/A & 0 & 0 & N/E & NS & - \\
\hline Land use & $\mathrm{N} / \mathrm{E}$ & N/E & NS & N/E & ++ & N/E \\
\hline Agricultural output & N/E & NS & ++ & ++ & ++ & ++ \\
\hline Crop sales & N/E & $\mathrm{N} / \mathrm{E}$ & 0 & ++ & ++ & 0 \\
\hline Livestock by-products & N/E & N/E & + & N/A & N/A & 0 \\
\hline Non-farm enterprise (NFE) & NS & 0 & - & 0 & +++ & 0 \\
\hline \multicolumn{7}{|l|}{ Household welfare } \\
\hline Food security & +++ & N/A & +++ & +++ & +++ & +++ \\
\hline Consumption & NS & +++ & + & +++ & +++ & ++ \\
\hline Dietary diversity & 0 & +++ & NS & N/E & ++ & + \\
\hline $\begin{array}{l}\text { Home consumption of crop } \\
\text { production }\end{array}$ & $\mathrm{N} / \mathrm{E}$ & +++ & N/E & NS & + & $\mathrm{N} / \mathrm{E}$ \\
\hline
\end{tabular}

Note: $N / A$ not available, $N / E$ not estimated, $N S$ no shift, 0 overall mixed shift. $+=$ significant positive impact; and - = significant negative impact. One, two or three '+' or '-' signs refer to the level of the impact

mary coping mechanism for a quarter of the negative shocks among SCTP beneficiary households, and there are declines in ganyu labor and in the use of savings as coping mechanisms. The authors also found a smaller percentage of households engaging in coping mechanisms for negative shocks, particularly for the poorest households (Handa et al. 2015). In Ethiopia, the SCTPP reduced the number of hours per day children were engaged in household activities. In particular, children aged 6-12 in beneficiary households worked fewer hours per day on the family farm and across all other activities compared to those in control households (Asfaw et al. 2015a). However, the impact was more mixed in Lesotho: while boys 13-17 may have seen a reduction in engagement in paid work outside the house, girls have seen an increase due to the CGP (Pellerano et al. 2014). Pellerano et al. (2014) found a 
reduction in the levels of engagement in occasional and irregular occupations among adults, noting the results to indicate that the cash support effectively worked as a safety net preventing households from depending on low paid and precarious occupations. The authors also found CGP beneficiaries to be less likely to send children to live elsewhere by 6 pp., send children to work by 3 pp., take children out of school by 8 pp., and reduce spending on health by 7 pp. as a response to shocks within 12 months previous to the survey.

The decreased need to engage in negative risk coping mechanisms as a result of cash transfers was also shown through increases in enrolment and other educational outcomes for children. Handa et al. (2015) found that children aged 6-17 increased their net enrolment by $12 \mathrm{pp}$. as a result of the SCTP in Malawi, with slightly stronger impacts considering primary and secondary school-aged children separately. The authors also found the dropout rate to have dropped for primary school-aged children by $4 \mathrm{pp}$. and temporary withdrawal (missing more than two consecutive weeks of instruction at any time in the past 12 months) to have decreased by $5 \mathrm{pp}$. By the endline in Ethiopia, Berhane et al. (2015) found the SCTPP to have raised enrolment by around 6 pp. pp. in Hintalo-Wajirat, with the effect for girls particularly strong (13 pppp). Instead of having to take time out of school to earn extra income, children were more readily participating in school thanks to the SCTPP. In Ghana, the LEAP programme reduced the likelihood of school-aged children (5-17) missing any school by 8 pppp and also reduced the chance of missing an entire week by 5 pppp (Handa et al. 2014). Among younger children smaller households appeared to be more protective, with a larger impact on missing any school in smaller households. However, the significant impact on enrolment is entirely driven by larger households. Handa et al. (2014) also found the impact on secondary enrolment for children aged 13-17 to be similar to estimates for South Africa's Child Support Grant (6 pp) and Kenya's CT-OVC (8 pp). While there were mixed results for engagement in paid work with the Lesotho CGP, the programme increased the proportion of children aged 6-19 enrolled in school by 5 pp., with a larger impact on older boys aged 13-17 (Pellerano et al. 2014). AIR (2013) noted that children living in a CGP beneficiary household in Zambia were $1 \mathrm{pp}$. more likely to ever enroll in school and 2 pp. more likely to enroll on time, for every year less of education their mother has. The authors attribute this effect to the CGP enabling or motivating mothers who did not enroll children in school at baseline to change their actions and start enrolling their children in school.

Cash transfer programmes were found to strengthen community ties through various channels, while the impact on private transfers was mixed. In Lesotho, the CGP had a significant impact in strengthening the reciprocity arrangements around food sharing in treatment villages. Both the proportion of households receiving and the proportion providing in-kind help in the form of food increased as a consequence of the programme. The impact is strong and significant, 15 and $18 \mathrm{pp}$. respectively, and the magnitude is larger for households with no labour capacity (Daidone et al. 2014b). Handa et al. (2014) found a positive impact on the value of gifts received and the amount of credit extended to others in Ghana. Meanwhile, in Malawi Asfaw et al. (2015b) found SCTP beneficiary households to be $4 \%$ points 
less likely to receive a transfer. In Ethiopia, Asfaw et al. (2015a) found increases in social capital and subjective belief of individuals' quality of life and control. Treated households were more likely to agree with additional support to poor people, have fewer problems with neighbors, and, similarly, agree that people residing in their community are basically honest and trustworthy. Other opinions of life satisfaction and ability to achieve success marked higher among male-headed beneficiary households compared to male-headed control households. However, there were no impacts observed in either receipt or giving of private transfers in Ethiopia.

Beneficiary households were also found to use proceeds from cash transfer programmes to pay off debts. In Ghana, Handa et al. (2014) observed beneficiary households saving more and being more likely to repay debt; smaller beneficiary households also reduced their likelihood of holding a loan by $9 \mathrm{pp}$. The authors also found a corresponding significant impact on the amount paid off of $19 \mathrm{pp}$. of adult equivalent consumption. In Malawi, households overall, and female-headed households and large farm households in particular, reduced debt from previous loans due to the SCTP. Male-headed households and large farm households were also less likely to still owe money for previously contracted loans (Asfaw et al. 2015b). Daidone et al. (2014a) also found larger households to pay down loans as a result of the CGP in Zambia.

\subsection{Can Cash Transfer Contribute to Managing Climate Risk?}

Climate change poses severe threats to households' wellbeing across the world, particularly in low-income countries where poor households are often exposed to different sources of risk. Adoption of risk management strategies, such as the promotion of social safety nets, are becoming gradually more relevant for improving the households' abilities to manage climate risk. Given the high incidence of climate shocks in Zambia, we also would like to present the findings of Asfaw et al. (2016) who shed light on how households respond to the CGP cash transfer in a context of weather instability. Asfaw et al. (2016) conducted additional analysis by merging the Zambia CGP impact evaluation data with rainfall data obtained from the Africa Rainfall Climatology v.2 (ARC2) (1983-2012). ${ }^{1}$ They assessed whether regular and unconditional small cash payments (via the CGP) helped mitigate the negative effects of climate variability, protect and improve smallholders' livelihoods and ensure food security and nutrition. ${ }^{2}$ The authors also investigated how the CGP and climate variability affect households on different quintile of the welfare and food security dimensions.

Asfaw et al. (2016) found the CGP to increase total/food and non-food expenditure, which implies the treatment increases households' welfare. As a result of an

\footnotetext{
${ }^{1}$ Dekads (i.e. 10 days) at $0.1^{\circ}$ covering the period 1983-2012 at ward level.

${ }^{2}$ The outcome variables in the study included total expenditure, food/non-food expenditure, daily caloric intake and dietary diversity index.
} 
increase in food expenditure, both quantity and quality of food consumed responded positively to CGP receipt, implying that households benefitted from the CGP in terms of food security and nutrition. With regards to the effect of climatic variables on welfare and food security, results from Asfaw et al. (2016) show that overall, households in areas that experienced lower than average rainfall had lower levels of daily caloric intake as well as food and non-food expenditures, and this effect was most pronounced for the poorest households in the sample. A possible explanation could be that the decline in rainfall had an initial negative impact on agriculture, livestock production and other water-intensive activities. The decline in volume of production thus affected households' purchasing power, forcing them to improve their coping mechanisms.

This study also finds strong evidence that cash transfer programmes have a mitigating role against the negative effects of climate shocks. Households that participated in the CGP had much lower negative effects of the weather shock, with poorest households gaining the most. This indicates the potential of social protection to support food access for households exposed to climate risk. However, the analysis also indicates that while participation in the CGP is beneficial in mitigating negative effects of climate shocks on food security, it is not sufficient to fully overcome these effects. Thus it is important to ensure that SCTs are well aligned with other forms of livelihood programmes and climate risk management, including disaster risk reduction activities. This result confirms the findings of authors like Eriksen et al. (2005), who found a positive relationship between the ability of people to draw on extra sources of income and the ability to withstand droughts in Tanzania and Kenya, with respect to those who were not.

\subsection{Potential of Cash Transfer to Promote Ex-Ante Risk Management}

Cash transfers contribute to ex-ante risk management by increasing household adaptive capacity through accumulation of productive assets, increased crop and livestock production and productivity, and linkages with output markets. We look at various dimensions of the productive process in order to ascertain whether households were found to have increased spending in livelihood activities, including crop production, crop input use and asset building. Given that agriculture represents the primary economic activity of the households studied, investment in agricultural assets and increases in crop production prove critical for strengthening livelihoods and ex-ante risk management. Households can also enhance their resilience by diversifying into different income streams, such as non-farm enterprises. Table 2 presents the cross-country summary of the impact of SCTs on investment in livelihood activities. 


\subsubsection{Impacts on Accumulation of Productive Assets}

Beneficiary households overall (and larger sized households in particular) in Zambia owned more axes and hoes, and were more likely to own hammers, shovels, and ploughs as a result of the cash transfer programme (Daidone et al. 2014a). Beneficiary households in Kenya were more likely to own troughs, and male-headed households were also more likely to own machetes and sickles (Asfaw et al. 2014). In Lesotho, Daidone et al. (2014b) found the CGP to increase the use and purchase of scotch-carts. In Malawi, beneficiary households overall, both female and maleheaded households, and large farm households owned more agricultural implements (Asfaw et al. 2015b). Handa et al. (2015) also found the SCTP to increase crop production and agricultural assets (sickles in particular). In terms of agricultural asset ownership, beneficiary households in Hintalo-Wajirat were 6 pp. and 7 pp. more likely to own plows and imported sickles, respectively (over baseline shares of $47 \%$ and $41 \%$ ). In contrast, beneficiary households in Abi Adi were less likely to own those agricultural implements. In terms of number owned, there were more negative effects throughout (Asfaw et al. 2015a). However, Berhane et al. (2015) found the SCTPP in Ethiopia to increase a constructed farm productive assets index by $2 \%$ in Hintalo-Wajirat.

Cash transfers also led to increased livestock ownership in SSA, particularly of smaller animals. Both small and large beneficiary households in Zambia increased livestock ownership, but the impacts were stronger for large households (Daidone et al. 2014a). Smaller households and female-headed households in Kenya increased their ownership of small livestock (such as sheep and goats) compared to control households. For smaller households, there was about a $15 \mathrm{pp}$. increase in ownership of small livestock compared to control households, while female-headed households receiving the transfer increased their ownership by 6 pp. (Asfaw et al. 2014). Daidone et al. (2014b) also found the cash transfer in Lesotho to have increased the proportion of households owning pigs by about $8 \mathrm{pp}$. as well as to have increased the number of pigs owned by $0.1 \mathrm{pp}$. Whether by number of livestock owned or livestock ownership, SCTP beneficiaries in Malawi faced increases on livestock (also noted by Handa et al. (2015)), such as on chickens, goats and sheep, and pigs (Asfaw et al. 2015b). Meanwhile, in Ethiopia Asfaw et al. (2015a) found the impact on livestock ownership to be more mixed, depending particularly on the area in which the transfer was given. Berhane et al. (2015) found the SCTPP in Ethiopia to increase the likelihood that households own any form of livestock by $7 \%$ in HintaloWajirat, with the increase largely driven by the increase in poultry ownership.

\subsubsection{Impacts on Crop Production and Productivity}

The cash transfer programmes evaluated generally led to increased crop production and productivity. Aggregating all crop output by value, the GCP in Zambia increased the value of all crops harvested by ZMK 146, approximately a 50\% increase from baseline, with a larger value increase for smaller households at ZMK 182. 
Beneficiary households increased their crop production marketing by $12 \mathrm{pp}$. and also increased their average value of sales (Daidone et al. 2014a). Production of maize, the main staple commodity, increased in CGP households in Lesotho by around $39 \mathrm{~kg}$ more than the control group, and more so for households with more available household labour. Sorghum production increased by around $10 \mathrm{~kg}$, with a larger impact in severely constrained households, likely because sorghum requires less labour as compared to other major crops. Furthermore, results on home gardening were consistently larger for unconstrained and moderately labour-constrained households compared to households with no adult members fit to work (Daidone et al. 2014b). In Malawi, beneficiary households increased groundnut production and productivity, with fewer and mixed impacts on other crops. Medium farm households and male-headed households also increased maize yields. Ultimately, both male-headed households and medium farm households increased the value of crop production as a result of the SCTP. Households were more likely to sell any crop, and the value of crop sold increased for female-headed households, small farm households, and medium farm households (although it decreased for large farm households) (Asfaw et al. 2015b). In Ethiopia, Asfaw et al. (2015a) found households to have decreased their yield of sorghum but to have increased sorghum yields, particularly in Hintalo-Wajirat and among male-headed households. Ultimately, beneficiary households increased the total value of their crop production by $18 \%$. For the Kenya CT-OVC, Asfaw et al. (2014) found little impact of the programme on crop production. However, there was an impact on the proportion of food consumption coming from own production, particularly for smaller-sized households and female-headed households. The average treatment effect for the share of consumption from home produced dairy and eggs was $20 \mathrm{pp}$. for smaller households and $15 \mathrm{pp}$. for female-headed households.

Increased crop production and productivity for beneficiary households also came through increases in land and crop input use. The CGP in Zambia increased the amount of operated land by about $34 \%$ from baseline, and $18 \mathrm{pp}$. more households spent money on inputs, from a baseline share of $23 \%$. This increase in money spent on inputs was particularly relevant for smaller households (22 pp), and included spending on seeds, fertilizer and hired labour. The increase of $14 \mathrm{pp}$. in the proportion of small households purchasing seeds is equivalent to more than a doubling in the share of households. Small beneficiary households spent ZMK 42 more on crop inputs than the corresponding control households, including ZMK 15 on hired labour, amounting to three times the value of the baseline mean for overall spending, and four times for hired labour (Daidone et al. 2014a). The CGP in Lesotho significantly increased the share of beneficiary households using pesticides ( $8 \mathrm{pp}$ ), especially those who are labour-unconstrained and who are also more likely to purchase pesticides as a result of receiving the CGP. Households purchased seeds more often (7 pp), although there was no statistically significant change in the intensity of purchase (Daidone et al. 2014b). In Malawi, household expenditure on organic fertilizer increased by MWK 158 (from a baseline of MWK 245). Increases on organic fertilizer expenditure also were found at the disaggregated levels (aside from medium farm households, which faced no increase) and at expenditure-per-acre 
(Asfaw et al. 2015b). An increase in the likelihood of chemical fertilizer use is also found among male-headed households. In the case of the Ethiopia SCTPP, femaleheaded beneficiary households were $4 \mathrm{pp}$. more likely to practice a soil and water conservation technique on their land, a noticeable increase on their baseline mean of $14 \%$. Female-headed households were also 3 pp. more likely to hire labour for farm work from a low baseline mean of 5\% (Asfaw et al. 2015a).

\subsubsection{Impacts on Non-farm Enterprises}

On non-farm enterprises cash transfer programmes were found to have mixed results. In Zambia, non-farm work increased by 20 days overall among beneficiaries and non-farm enterprise by 1.6 days (AIR 2013). Cash beneficiary households participated more often in non-farm enterprises in Kenya if they were female-headed, but less so if they were male-headed; otherwise, there was no impact recoded for the overall sample (Asfaw et al. 2014). In Malawi, results on non-farm enterprise labor were mixed, where beneficiary households were less likely to engage in charcoal/ firewood enterprises but were more likely to engage in petty trade enterprises (Asfaw et al. 2015b). In Ethiopia (Asfaw et al. 2015a) and in Ghana (Handa et al. 2014) there were no impacts found on the overall level on the likelihood that households participated more or less often in non-farm enterprises. Pellerano et al. (2014) found a reduction in the proportion of households with an enterprise in operation in the 30 days prior to the survey, but noted that the reduction was mainly driven by households engaging less frequently in home brewing, which is generally small scale and a livelihood strategy of last resort.

\subsection{Can Cash Transfer Promote Resilience by Enhancing Food Security?}

Households consistently more able to consume an adequate amount of food and a more diverse basket are necessarily more resilient and less food insecure than otherwise similar households. Depending on the availability of data across the different countries, we collected the impacts of cash transfer programmes on consumption, dietary diversity and subjective food security indicators. Table 2 presents the crosscountry summary of the impact of social cash transfers on food security, consumption and diet diversity.

\subsubsection{Impact on Food Security}

As expected, the studied cash transfer programmes unambiguously increased the food security of beneficiary households. The CGP in Zambia increased the percentage of households eating two or more meals per day by $8 \mathrm{pp}$. as well as the number 
of households that were not severely food insecure by 18 pp., (AIR 2013). The share of households consuming from part of their harvest also increased by $6 \mathrm{pp}$., which came from increased groundnut and rice consumption of home production (Daidone et al. 2014a). In Lesotho, Pellerano et al. (2014) found the CGP to reduce the number of months that households experienced shortages of food and decrease the proportion of households not having enough food to meet their needs at least for one month in the previous 12 months. Food security also increased in Malawi thanks to the cash transfer programme: households overall, for example, were $11 \mathrm{pp}$. less likely to worry whether they would have enough food in the past seven days. The SCTP also allowed households to eat more meals per day, with effects observed for households at all levels except for large farm households. Medium farm households also increased the number of months that last year's maize harvest lasted (Asfaw et al. 2015b). In Ethiopia, there was a reduction on the number of months with problems satisfying food needs in the overall sample and among male-headed households. There was no impact on number of months in the last 12 months that the household ran out of home-grown food, but there were increases on both the number of times a day children ate in the household and the number of times adults ate in the household. Compared to control households, beneficiary households were also less likely to suffer a shortage of food to eat during the last rainy season as a result of the SCTPP. With regards to measures of last resort, beneficiary households reduced their likelihood of consuming seed stock during the last week, compared to control households (Asfaw et al. 2015a).

\subsubsection{Impact on Consumption Expenditure}

Cash transfers also enabled households to better meet their consumption needs. In Zambia, the programme significantly increased food spending, with the largest share going to cereals, followed by meats, including poultry and fish, followed by fats such as cooking oil and then sugars (AIR 2013). The share of households consuming from part of their harvest also increased by $6 \mathrm{pp}$., which came from increased groundnut and rice consumption of home production (Daidone et al. 2014a). In Lesotho, Pellerano et al. (2014) detected a statistically significant CGP effect on food expenditure and total consumption when controlling for covariates, including differences in prices across locations, but at low levels of significance. In Kenya, although there was no significant impact on consumption expenditure of cereals and legumes, there was an increase for food spending on dairy and eggs. The programme had no effect on spending on most of the food consumption categories for larger households but it had large increases on three of the outcomes (dairy and eggs, meat and fish and fruit) for smaller households. The programme had larger and positive impacts on female-headed households compared to male-headed households, as in the case of the share of consumption from home produced dairy and eggs. Treated households in Kenya also appeared to consume more animal products, as well as other foods, from their own production compared to control households (Asfaw et al. 2014). In Malawi, there were increases at all levels of daily per capita calories 
consumed, with those increases in calories coming from food purchases; aside from a decrease for male-headed households, there are no impacts on calories coming from own production. Such results suggest that households are likely using the cash to buy food directly, although calories coming from own production may take more time to see impacts. For both extremely-poor and non-extremely poor household, the pattern holds up: increases in calories consumed come from purchases rather than from own production, with decreases in calories consumed coming from gifts and other sources (Asfaw et al. 2015b). Berhane et al. (2015) found the SCTPP in Ethiopia to reduce the food gap, increase the availability of calories, and to reduce seasonal fluctuations in children's food consumption (Berhane et al. 2015). Meanwhile, Handa et al. (2014) found in Ghana that there was no overall change in food consumption between treated and control households.

\subsubsection{Impact on Dietary Diversity}

There is also some evidence of improved dietary diversity as a result of cash transfer programmes. There was a clear shift away from roots and tubers (primarily cassava) and toward protein (dairy, meats), indicating a possible improvement in dietary diversity among CGP recipients in Zambia (AIR 2013). In smaller households, the impact of the CGP on food expenditures was concentrated on cereals (where $45 \%$ of the impact on food is derived) followed by meat (15\%), fats $(14 \%)$, and pulses $(13 \%)$. Among larger households, the impact of the grant on food expenditures is driven by meats $(32 \%)$ and then cereals $(30 \%)$. In the end, food expenditures increase for both groups of households as a result of the cash transfer programme (Daidone et al. 2014a). In Kenya, the results showed no significant impact on consumption expenditure of cereals and legumes. However there was about a $12 \mathrm{pp}$. increase for food spending on dairy and eggs. The programme had no effect on spending on most of the food consumption categories for households with larger number of members but it had large, positive, and significant effects on three of the outcomes (dairy and eggs, meat and fish and fruit) for smaller sized households. The programme typically had larger and positive impacts on female-headed households compared to male-headed households, such as on consumption of animal products. Treated households also appear to have consumed more animal products, as well as other foods, from their own production compared to control households. Dairy and eggs consumption from own production increased by about $13 \mathrm{pp}$. for beneficiary households, and the impact on other types of foods was about $4 \mathrm{pp}$. The average treatment effect for the share of consumption from home produced dairy and eggs was $20 \mathrm{pp}$. for smaller households and $15 \mathrm{pp}$. for female-headed households (Asfaw et al. 2014). In Ethiopia, results from Asfaw et al. (2015a) showed an increase in household consumption of oils and fats, sweets, and spices, condiments, and beverages as a result of the SCTPP. This was mixed with reductions in household consumption of fruits and meats. Berhane et al. (2015) found the SCTPP to have improved diet quality, as measured by the Dietary Diversity Index, in both May 2012 and May 2014 by $13 \%$ and 12\% respectively. In Ghana, although there was no 
overall change in food consumption between treated and control households, Handa et al. (2014) found a significant decline in starches and meats and an increase in fats and food eaten out. Smaller households also faced a decline in alcohol and tobacco consumption. Among Lesotho CGP beneficiaries, the increased spending on dairy and eggs (as well as meat/fish and fruit for smaller households) did not translate into an impact on dietary diversity (Pellerano et al. 2014).

\section{Conclusions and Implications}

The analysis of impact evaluation studies show that cash transfer programmes overall have important implications for household resilience. By providing a steady and predictable source of income, cash transfer programmes can build human capital and improve food security and potentially strengthen households' ability to respond to and cope with exogenous shocks, and allow them to diversity and strengthen their livelihoods to prevent future fluctuations in consumption. Many of the programmes studied increased investment in agricultural inputs and assets, including farm implements and livestock. Beneficiaries in the studied country programmes generally increased crop production and value of crop production. Although differing across countries, food security indicators revealed increases in the proportion of households being food secure as a result of cash transfer programmes. This too was met by increases in consumption and dietary diversity. Although the impacts on risk management are less uniform, the cash transfer programmes seem to strengthen community ties (via increased giving and receiving of transfers) allow households to save and pay off debts, and decrease the need to rely on adverse risk coping mechanisms. Finally, the case study of the CGP in Zambia demonstrates the potential for cash transfers to help poor households manage climate risk. Not only was CGP receipt associated with increases in total/food and non-food expenditure, and subsequently the quantity and quality of food consumed, but the CGP was also found to benefit households even when they were facing climate shocks. The CGP's climate mitigating effect is particularly evident for households at the lowest quintiles of the distribution, meaning that the CGP better protects poorer households against climate variability than richer households. Thus cash transfers can improve poor households' resilience for an uncertain future in terms of climate change.

The differences in impacts across countries can be attributed to a variety of factors, including the availability of labour given the demographic profile of beneficiary households, the relative distribution of productive assets, the local economic context, the relevance of messaging and soft conditions on spending and the regularity and predictability of the transfers themselves. In the case of LEAP in Ghana, irregular payments may have prevented households from increasing consumption, as consumption is driven by permanent income. Instead, the lumpy flow of cash seems to have promoted declines in the number of households with outstanding loans and increases in the number of households with savings. In Ethiopia, the SCTPP targeted households that were particularly made up with either the elderly 
or youth, which may explain why beneficiary households did not face increases in labour supply or on other dimensions of agricultural production. The amount offered through the Ethiopia SCTPP as a percentage of per capita income is also not as high compared to cash transfer programmes that have found widespread impacts.

Cash transfers can be more than just social assistance; not only can they help vulnerable households avoid the worst effects of severe deprivation, they can also contribute to economic and social development. Since cash transfer programmes impact the livelihoods of households, articulation with other sectoral development programmes in a coordinated rural development strategy could lead to synergies and greater overall impact. Complementary measures to maximize the positive spillover effects of the income multiplier generated by the cash transfer programme should be targeted not only at cash transfer beneficiary households, but also at ineligible households that provide many of the goods and services in the local economy. However, the potential productive impact of the cash transfer is sensitive to implementation, and delays and irregularities in payment can reduce its effectiveness in terms of helping households invest and manage risk.

Existing social protection programmes rarely takes into account climate risk in their design and implementation. Being poverty reduction instruments, social safetynet interventions tend to target mainly economic (wealth and income) criteria. Including environmental risks and vulnerabilities as targeting criteria could help improve the effectiveness of safety nets as risk-coping instruments. This could be done by developing maps of poverty and climate change vulnerability hotspots or by ensuring effective linkage between social protection management and information and early warning systems. Public works programmes, including productive safety nets, can be designed in ways that simultaneously contribute to increasing household incomes, engaging communities in climate-smart agriculture and generating 'green jobs' in areas such as waste management, reforestation and soil conservation.

\section{References}

Alinovi, L., d'Errico, M., Mane, E. \& Romano, D. 2010. Livelihoods strategies and household resilience to food insecurity: an empirical analysis to Kenya. European Report on Development. Available at erd.eui.eu/publications/erd-2010-publications/background-papers/ livehoodsstrategies-and-household-resilience-to-food-insecurity.

American Institutes for Research (AIR). (2013). 24-Month Impact Report for the Child Grant Programme. Washington DC, USA.

Antonaci, L., Demeke, M. and Soumare, M.S. (2012). Integrating risk management tools and policies into CAADP: Options and Challenges. FAO-NEPAD policy brief.

Asfaw, S., Covarrubias, K., Davis, B., Dewbre, J., Djebbari, H., Romeo, A. and Winters, P. (2012). Analytical Framework for Evaluating the Productive Impact of Cash Transfer Programmes on Household Behaviour: Methodological Guidelines for the From Protection to Production Project. Paper prepared for the From Protection to Production project. Rome, UN Food and Agriculture Organization.

Asfaw, S., Davis, B., Dewbre, J., Handa, S. and Winters, P. (2014). Cash transfer programme, productive activities and labour supply: Evidence from randomized experiment in Kenya. Journal of Development Studies, 50(8):1172-1196. 
Asfaw, S., Carraro, A. and Davis, B. (2016). The Role of Cash Transfers to Manage Climate Risk. The Case of Zambia. ESA working paper, forthcoming.

Asfaw, S., Pickmans, R., Alfani, F. and Davis, B. (2015a). Productive Impact of Ethiopia's Social Cash Transfer Pilot Programme, PtoP project report, FAO, Rome

Asfaw, S., Pickmans, R., \& Davis, B. (2015b). Productive Impacts of Malawi's Social Cash Transfer Programme - Midline Report. PtoP project report, forthcoming, FAO, Rome.

Berhane, G., Hoddinott, J., Kumar, N. and Taffesse, A.S., (2011). The impact of Ethiopia's productive safety nets and household asset building programme: 2006-2010. IFPRI, Washington DC. USA.

Berhane, G., Devereux, S., Hoddinott, J., Nega Tegebu, F., Roelen, K., and Schwab, B. (2015). "Evaluation of the Social Cash Transfers Pilot Programme Tigray Region, Ethiopia." Endline Report, IFPRI, Washington DC. USA.

Boone, R, Covarrubias. K., Davis. B. and Winters, P. (2013) Cash Transfer Programs and Agricultural Production: The Case of Malawi. Agricultural Economics, 44:365-378.

Covarrubias, K., Davis B. and Winters, P., (2012). "From Protection to Production: Productive Impacts of the Malawi Social Cash Transfer Scheme." Journal of Development Effectiveness, 4:1, 50-77.

Daidone, S., Davis, B., Dewbre, J. \& Covarrubias, K., (2014a). Lesotho Child Grants Programme: 24-month impact report on productive activities and labour allocation PtoP project report, FAO, Rome

Daidone, S., Davis, B., Dewbre, J., Gonzalez-Flores, M., Handa, S., Seidenfeld, D. \& Tembo, G. (2014b). Zambia's Child Grant Programme: 24-month impact report on productive activities and labour allocation PtoP Project Report, FAO, Rome.

Davis, B., Gaarder, M., Handa S. and Yablonski, J., (2012). "Evaluating the impact of cash transfer programs in Sub Saharan Africa: an introduction to the special issue." Journal of Development Effectiveness 4(1): 1-8

Davis, B. and Handa, S. (2015). How much do programmes pay? Transfer size in selected national cash transfer programmes in Africa. The Transfer Project Research Brief 2015-09. Chapel Hill, NC: Carolina Population Center, UNC-Chapel Hill.

Del Ninno, C., Subbarao, K., \& Milazzo, A. (2009). How to make public works work: A review of the experiences. World Bank, Human Development Network. Washington D.C.: World Bank.

Dercon, S., and Krishnan, P. (2003). Food Aid and In-formal Insurance. Center for the Study of African Economies Working Paper Series 2003-01.

Devereux, S., Marshall, J., MacAskill, J. and Pelham, L. (2005) 'Making Cash Count: Lessons from cash transfer schemes in east and southern Africa for supporting the most vulnerable children and households,' London and Brighton: Save the Children UK and the Institute of Development Studies.

Djebbari, H. and Hassine, N.B., (2011). Methodologies to analyse the local economy impact of SCTs. Report prepared for UNICEF-ESARO.

Eriksen, S.H., Brown, Kelly, P.M., The dynamics of vulnerability: locating coping strategies in Kenya and Tanzania - The Geographical Journal, Vol. 171, No. 4,2005, pp. 287-305

Fiszbein, A. and Schady, N. (2009) Conditional Cash Transfers for Attacking Present and Future Poverty, with Ferreira, F.H.G., Grosh, M., Kelleher, N., Olinto, P., and Skoufias, E., The World Bank Policy Research Report, 2009, Chapters 2, 5.

Gertler, P., Martinez, S. and Rubio-Codina, M. (2012) Investing Cash Transfers to Raise Long Term Living Standards. American Economic Journal: Applied Economics, 4(1), pp. 164-92.

Gilligan, D., Hoddinott J. and Taffesse, A. (2009) The Impact of Ethiopia's Productive Safety Net Program and Its Linkages. Journal of Development Studies 45(10), pp. 1684-1706.

Handa, S. and Park, M. (2012). Livelihood Empowerment against Poverty Program. Report, University of North Carolina at Chapel Hill.ae Report

Handa, S., Angeles, G., Abdoulayi, S., Mvula, P., Tsoka, M. et al. (2015) Malawi Social Cash Transfer Programme: Midline Impact Evaluation Report. Working Paper. Midline report, University of North Carolina, Chapel Hill, USA. 
Handa, S., Park, M., Osei Darko, R., Osei-Akoto, I., Davis, B. \& Daidone, S. (2014) Livelihood Empowerment Against Poverty (LEAP) Program - Impact evaluation report, Carolina Population Center, University of North Carolina.

Heckman, J.J., Ichimura, H. and Todd, P.E., (1997). "Matching as an econometric evaluation estimator: evidence from evaluating a job training program.” Review of Economic Studies, 64, pp. 605-654.

Khandker, R.K., Koolwal, G.B., and Samad, H.A., (2010). Handbook on impact evaluation: quantitative methods and practices. The World Bank, Washington DC., USA.

Maluccio, J. (2010). The Impact of Conditional Cash Transfers in Nicaragua on Consumption, Productive Investments and Labor Allocation. Journal of Development Studies, 46 (1),\%. 14-38.

Martinez, S. (2004) Pensions, Poverty and Household Investments in Bolivia. Doctoral dissertation, University of California, USA.

Pellerano, L., Hurrell, A., Kardan, A., Barca, V., Hove, F., Beazley, R., Modise, B., MacAuslan, I., Dodd, S. and Crawfurd, L., (2012). CGP impact evaluation: targeting and baseline evaluation report. OPM, January 10.

Pellerano, L., Moratti, M., Jakobsen, M., Bajgar, M.and Barca, V., (2014). Child Grants Programme Impact Evaluation: Follow-up Report. Oxford Policy Management (OPM), Oxford - April 2014

Rubin, D. B., (1980). Discussion of "Randomization Analysis of Experimental Data in the Fisher Randomization Test" Journal of the American Statistical Association, 75, 591-593.

Seidenfeld, D. and Handa, S. (2011). Zambia's Child Grant Program: Baseline Report, American Institutes for Research, Washington, DC., November.

Soares, F. V., Ribas, R. P., Hirata, G. I. (2010) The impact evaluation of a rural CCT programme on outcomes beyond health and education. Journal of Development Effectiveness, 2(1),\%. $138-157$.

Todd, J, Winters, P. and Hertz, T. (2010) Conditional Cash Transfers and Agricultural Production: Lessons from the Oportunidades Experience in Mexico. Journal of Development Studies, 46(1),\%. 39-67.

Ward, P., Hurrell, A., Visram, A., Riemenschneider, N., Pellerano, L. and MacAuslan, I. (2010). Kenya CT-OVC programme operational and impact evaluation 2007-2009. Oxford Policy Management, Oxford, UK.

Wooldridge, J.M. (2002) Econometric analysis of cross-section and panel data. Cambridge, MA: The MIT Press.

Open Access This chapter is distributed under the terms of the Creative Commons AttributionNonCommercial-ShareAlike 3.0 IGO license (https://creativecommons.org/licenses/by-nc-sa/3.0/ igo/), which permits any noncommercial use, duplication, adaptation, distribution, and reproduction in any medium or format, as long as you give appropriate credit to the Food and Agriculture Organization of the United Nations (FAO), provide a link to the Creative Commons license and indicate if changes were made. If you remix, transform, or build upon this book or a part thereof, you must distribute your contributions under the same license as the original. Any dispute related to the use of the works of the FAO that cannot be settled amicably shall be submitted to arbitration pursuant to the UNCITRAL rules. The use of the FAO's name for any purpose other than for attribution, and the use of the FAO's logo, shall be subject to a separate written license agreement between the FAO and the user and is not authorized as part of this CC-IGO license. Note that the link provided above includes additional terms and conditions of the license.

The images or other third party material in this chapter are included in the chapter's Creative Commons license, unless indicated otherwise in a credit line to the material. If material is not included in the chapter's Creative Commons license and your intended use is not permitted by statutory regulation or exceeds the permitted use, you will need to obtain permission directly from the copyright holder.

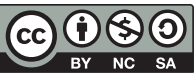

